\title{
FACTORS CONTROLLING DEALATION AND EGG LAYING IN VIRGIN QUEENS OF THE ARGENTINE ANT \\ LINEPITHEMA HUMILE (MAYR) (= IRIDOMYRMEX HUMILIS)
}

\author{
By Luc Passera and Serge Aron
}

\section{INTRODUCTION}

In most ant species, reproduction is restricted to mated dealated queens. The reproductive life of queens usually starts at the time of colony founding just after mating. However, before mating, virgin queens remain for a more or less long period within the mother nest accumulating energy, waiting for sexual maturity and the appropriate weather conditions required for nuptial flight (Passera and Keller, 1992). Little is known about the biology of virgin queens during this maturation period, especially concerning their ability to lay eggs. Nevertheless, egg laying by virgin queens is of interest because unfertilized eggs could be an important source of male production, especially in species in which the workers are sterile (Brian, 1979). Data concerning reproduction by virgin queens are available only for the genus Solenopsis (Tschinkel and Howard, 1978; Voss, 1981). Two studies have demonstrated that virgin queens of several species within the $S$. geminata species complex are prevented from shedding their wings and from laying eggs in the presence of the mated mother queen (Fletcher and Blum, 1981; Vargo and Porter, 1993).

In this paper we study egg laying by virgin queens in the Argentine ant, Linepithema humile, and we investigate the factors involved in the control of this process.

\section{Materials ANd Methods}

Like many other tramp species, the Argentine ant is a polygynous and polydomous species with sterile workers (Passera, 1992). There is no mating flight; mating rapidly occurs in the nest 2-3 days after the emergence of females, and colony founding is

Centre de Recherche en Biologie du Comportement, URA 664, Université PaulSabatier, 118 route de Narbonne, 31062 TOULOUSE Cedex, France

Manuscript received 11 January 1993 
accomplished by budding (Passera and Keller, 1992: Passera, 1992). Because there is no inter-colony hostility in this species, individuals can be shifted between colonies readily. It is thus extremely easy to set up replicate experiments.

Colonies used in this study originated from Port-Leucate on the western Mediterranean coast of France. After being brought to the laboratory, the ants were drawn out of the soil with the aid of a $100-\mathrm{W}$ incandescent lamp. They were housed in artificial nests covered with a black plastic box and maintained in the laboratory (Passera et al., 1988a). Under these conditions, queenless colony fragments rear sexuals (Passera et al., 1988a; Vargo and Passera, 1991). In order to obtain winged virgin queens, females were isolated in the pupal stage and kept apart from other individuals. When necessary, winged and wingless queens were dissected in water using a dissecting microscope; we verified if the queen was inseminated from the presence of sperm, and recorded the absence or presence of developing eggs in the ovarioles and whether or not they contained corpora lutea in their bases.

\section{RESULTS}

\section{Dealation}

To study dealation of virgin queens over time, 298 winged queens, 0 to $24 \mathrm{~h}$ old, were set up in 15 queenless units (mean $=20$ winged queens per nest; $\mathrm{SD}=9.8$, range $=4-42$ ) each containing about 600 workers; they were monitored weekly. Of these, 168 survived long enough to shed their wings. Fig. 1 shows that the time of dealation is very variable, occurring from the first to the fourteenth week $($ mean $=5.2 ; \mathrm{SD}=3.5)$.

\section{Queen control over dealation}

To determine whether mated queens play a role in the ability of virgin queens to dealate, we compared dealation of virgin queens in 2 different experimental conditions. In the first series of experiments, we introduced 14 to 20 virgin queens (mean $=17, \mathrm{SD}=3.1$ ) into 5 queenless units, whereas in the second series we introduced 11 to 20 virgin queens (mean $=17, \mathrm{SD}=3.1$ ) in 10 units each headed by 2 mated queens. All the virgin queens used were newly emerged (less than $24 \mathrm{~h}$ old). Dealation was monitored every 3 days for 3 weeks. Fig. 2 clearly shows that dealation was lower in 


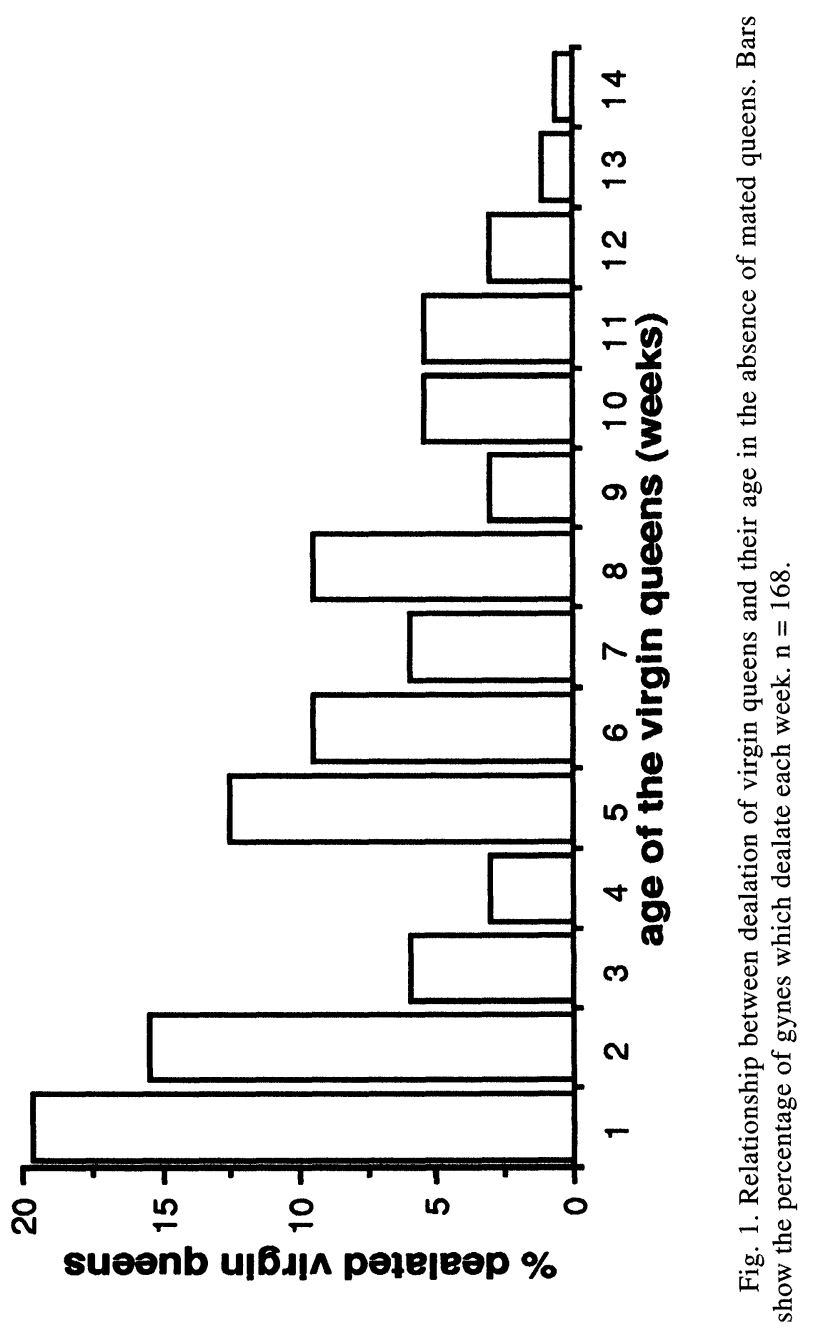




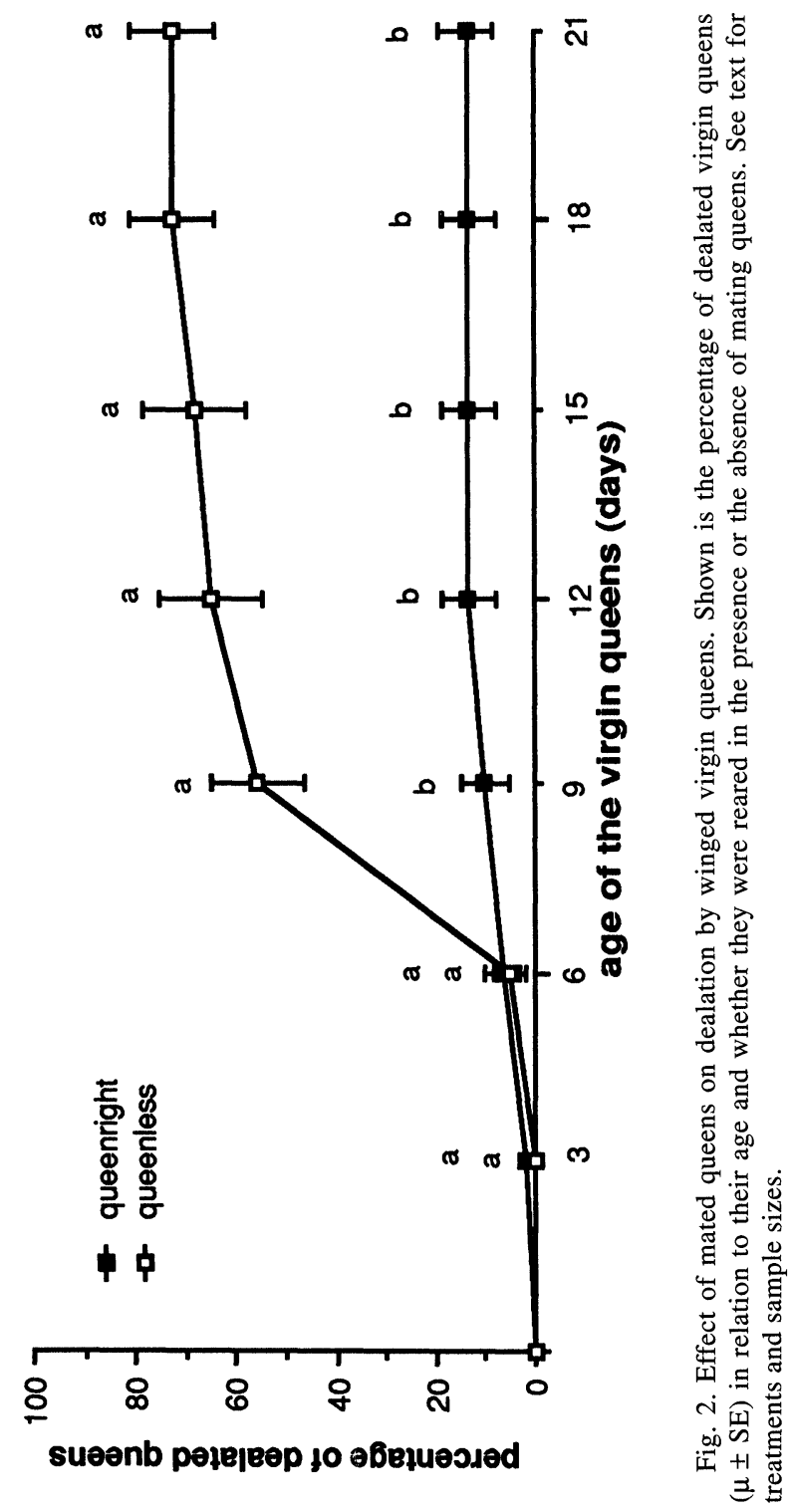


queenright units. After 3 weeks, $72.6 \%$ and $13.7 \%$ of virgin queens dealated in queenless and queenright units, respectively. The difference became statistically significant after day 9 (two-tailed, two-sample $t$-test $=4.59, P=0.0005$, square-root arc-sin transformed data).

Another experiment was performed using winged virgin queens reared in pairs in experimental units headed by a mated queen (10 replicates). The units were dequeened when the winged virgin queens were 7 weeks old, and the number of dealates present was recorded once a day (Fig. 3). In this case, almost $80 \%$ of the virgin queens shed their wings within 24 hours, and all of the 20 virgin queens involved in the experiment dealated before day 6 .

\section{Egg laying by virgin queens}

Within $24 \mathrm{~h}$ after emergence, 219 winged virgin queens were housed in 10 units occupied by queenless workers originating from the same natal nest (mean $=20$ virgin queens per nest; $S D=7.3$, range $=10-31)$. Egg laying was monitored daily for 8 weeks and later twice a week for 6 additional weeks. After each observation, the observed dealated queens were removed from the experiment. In addition, 3 winged virgin queens were dissected each week. Even after 14 weeks, no eggs were observed in any of the 10 experimental nests occupied by alates. All the dissections revealed that the spermathecae were empty, and in each case the ovaries were undeveloped and chorionated eggs were absent.

The situation was different after dealation. Dealated virgin queens less than 15 days old $(n=211)$ were set up in 21 experimental nests with queenless workers (mean $=10$ virgin queens per nest, $\mathrm{SD}=9$, range 1-33). Eggs were produced in all the 21 nests. Once the first eggs were laid, 1 virgin queen originating from each nest was dissected. All of the 21 queens had empty spermatheca but showed developed ovaries: their ovarioles contained chorionated eggs and small corpora lutea, indicating that they had laid eggs. The eggs were elliptical and pearly white. Their mean size was $0.3 \mathrm{~mm}$ long by $0.2 \mathrm{~mm}$ wide. They were very similar in size, shape and color to those laid by mated queens.

The time needed for vitellogenesis to occur in dealated virgin queens was assessed in 8 subcolonies. It was compared to the time needed in 26 subcolonies containing newly mated queens. After 


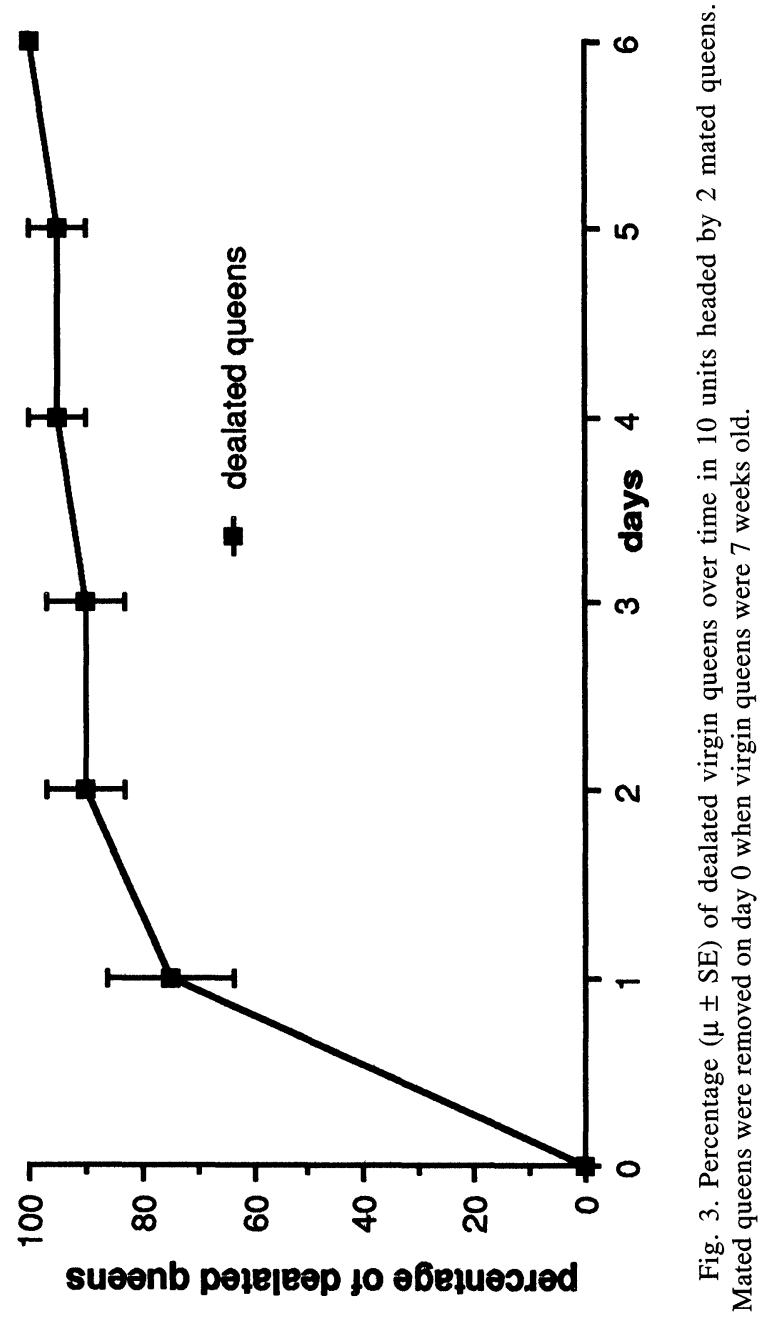


dealation, all the subcolonies were monitored daily and the time at which the first eggs were laid was recorded (Fig. 4). This delay was longer in virgin queens than in their mated counterparts: egg laying occurred after 17.8 days \pm 4.9 and 10.8 days \pm 4.7 in virgin and mated queens, respectively (two-tailed two-sample $t$-test $=3.8$, $P=0.0006, \mathrm{DF}=32$, square-root transformed data).

The development of eggs was monitored in 9 experimental subcolonies headed by virgin queens. All of these nests reared only males, which emerged 47 to 63 days after the beginning of egg laying. In two nests, males were able to mate with the dealated virgin queens (their mother), and workers emerged 1.5 months later. Two queens were dissected and had their spermathecae full of sperm indicating that they were mated.

\section{Behavior of newly dealated virgin queens}

Winged virgin queens were rarely seen outside the nest. Within 21 days, we daily observed several dozen winged virgin queens, corresponding to 2760 occasions to locate the gynes. Only 6 times $(0.2 \%)$ were winged virgin queens observed outside the nest, under the plastic box sheltering the nest. This behavior was suddenly altered at the time of dealation. Among 26 virgin queens observed

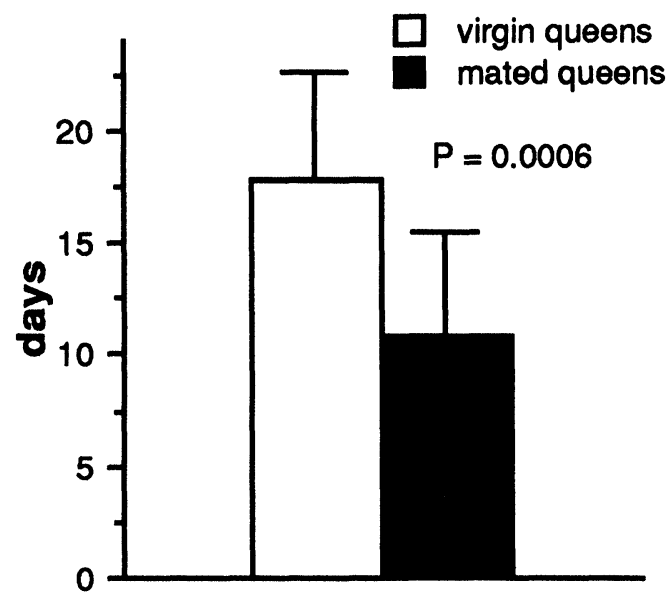

Fig. 4. Time delay between dealation and egg laying in 8 subcolonies containing virgin queens and 26 units containing newly mated queens. Shown are means \pm SD. 
daily after they had shed their wings, $16(61.5 \%)$ were seen outside the nest one day after dealation. This behavior faded rapidly later on, and the virgin queens were all seen inside the nest 8 days after dealation.

\section{Discussion}

The data reported in this paper are in agreement with those reported in several species of the genus Solenopsis by Fletcher and Blum (1981, 1983) and Vargo and Porter (1993). As observed in $S$. invicta and $S$. richteri, virgin queens of the Argentine ant are inhibited from shedding their wings in the presence of mated queens. However, the effect of queenlessness seems less pronounced than in Solenopsis: in S. invicta, dealation occurred in more than $60 \%$ of the virgin queens within 72 hours following dequeening (Fletcher and Blum, 1981). Similarly, $75 \%$ of virgin queens dealated within 1 week in queenless groups of S. richteri (Vargo and Porter, 1993). In our experiments, winged virgin queens of $L$. humile seem to react much more slowly than those of Solenopsis species when they were reared and maintained in queenless nests; only $20 \%$ of these virgin queens dealated within the first week. However, the difference is not so great if the age of the tested virgin queens is taken into account. In Solenopsis species the authors used virgin females of unknown age but most of them were several days or several weeks old. By contrast, our first experiment was conducted with virgin queens 1 day old at the time of dequeening. Our second experiment involved virgin queens 7 weeks old and gave similar results to those obtained in Solenopsis: all the virgin queens dealated within one week. We can hypothesize that in both genera, the older virgin queens dealated more easily than the younger ones did.

In $S$. invicta several studies have demonstrated that a primer pheromone produced by the mated queens inhibits dealation of virgin queens (Fletcher and Blum, 1981, 1983). The amount of the inhibitory pheromone is linked to the weight and the fertility of the inseminated queens (Willer and Fletcher, 1986). Evidence was reported by Sorensen et al. (1985) that this non-volatile substance is distributed to virgin queens by workers after physically contacting the mated queens. The role of such a queen pheromone, 
inhibiting dealation in L. humile, can be hypothesized, but we have no experimental evidence. The rather weak sensitivity of virgin queens to inhibitory factors produced by mated queens is consistent with the low number of mated queens still alive when virgin queens emerged. It is known that more than $90 \%$ of mated queens are executed by the workers before the rearing of queen larvae leading to a new cohort of virgin queens (Keller et al., 1989).

Egg laying by virgin queens is rather common among ants, but authors generally have not paid attention to whether the egg laying queens have shed their wings. In Aphaenogaster fulva aquia Haskins and Enzmann (1945) observed that wingless virgin queens produced eggs, but these authors give no information about egg laying by winged females. Results are similar for Lasius flavus (Goetsch and Kaethner, 1937), Leptothorax nylanderi (Plateaux, 1970), Messor ebeninus (Tohmé, 1975) and Temnothorax recedens (Dejean, 1974). In Monomorium pharaonis Buschinger and Petersen (1971) and Petersen and Buschinger (1971) reported that on at least one occasion oviposition began just after wing shedding.

The total lack of vitellogenesis and, as a consequence, the absence of oviposition in winged virgin queens of the Argentine ant is an important finding. Although it is possible that maturation of the ovaries is a long process resulting in the absence of egg laying, this is not the case in the Argentine ant: females reach sexual maturity within 2-3 days after emergence, and oviposition begins a few days after mating and dealation (Passera and Keller, 1992). As our results show, virgin queens retained their wings for several months and never oviposited. The link between dealation and the initiation of oviposition occurs in Solenopsis invicta but it is less pronounced in this latter species. Fletcher and Blum (1983) reported that $20 \%$ of the overwintered virgin alates were ovipositing in queenright field colonies. In contrast, their counterparts reared in spring did not lay eggs. These data demonstrate that egg laying by virgin alates in S. invicta is possible for virgin queens that remained in the nest for several months, whereas in the Argentine ant egg laying does not occur no matter how old the virgin alates.

Virgin queens are also known to lay trophic (non-embryonated) eggs which are eaten by workers and larvae. For example, in Pheidole pallidula unmated queens (winged or wingless) lay trophic 
eggs in queenright or queenless societies (Passera, 1978). The eggs laid by virgin queens are much larger than the reproductive ones laid by mated queens, and they are always non-embryonated (Passera, 1978). In S. invicta dealated virgin queens lay embryonated eggs as well as trophic eggs, both being the same size (Kearney et al., 1977; Voss, 1981). Nevertheless, most of them are trophic eggs since less than $10 \%$ are viable (Vargo and Ross, 1989). In the Argentine ant, we cannot identify two categories of eggs with respect to their size, because no attempts have been made to separate viable and non-viable eggs (by staining the chromatine, for example); therefore, we do not know if trophic eggs are laid by virgin queens.

Another interesting feature is that ovarian development is stimulated by wing shedding in L. humile. Mating is not necessary to accomplish this physiological event although egg laying is triggered more rapidly after insemination. In the Argentine ant virgin queens require 17.8 days after dealation to undergo vitellogenesis, whereas this period is only 10.8 days when dealation follows mating. Our data are similar to those reported for S. invicta. In this species ovarian development is faster in mated queens than in virgin dealated queens; it requires 2-3 days in the former case (Markin et al., 1972) compared to 9-12 days in the latter (Glancey et al., 1981). These data suggest that mating plays a role in accelerating ovarian development but not in triggering it.

The shedding of the wings is also responsible for the dramatic behavioral changes observed in virgin females of $L$. humile. During the week following dealation, queens were frequently observed outside the nest. This behavior could be linked to an increase in the aggressiveness of the workers. Indeed, we showed that virgin alates are often attacked and killed by their workers (Passera and Aron, 1993). In S. invicta and S. richteri many reproductively active virgin wingless queens are executed during the week following dealation (Fletcher and Blum, 1981; Vargo and Porter, 1993).

Does reproduction by virgin queens play a significant role in the biology of the Argentine ant? Considering the low number of unmated queens in field colonies $(2.1 \%$, Keller and Passera, 1992) and their weak fecundity, their contribution to male production is insignificant. The situation is quite different in S. invicta, in which the proportion of functional unmated queens in the polygynous 
form ranges from 26 to $30 \%$ (Vargo and Fletcher, 1987) and can reach $50 \%$ (Lofgren and Williams, 1984). In this species virgin queens may constitute an important source for male production. In the Argentine ant the advantage would thus lie elsewhere. This species moves rapidly and very often in response to environmental variation (Newell and Barber, 1913). Nest moving can result in dispersal and isolation of virgin queens in nest fragments deprived of mated queens and males. Under such conditions, our results indicate that virgin queens dealate and soon lay viable eggs. Males reared from these eggs are capable of mating with the virgin queens, allowing the inseminated queens to become efficient reproductive females. This biological event can be compared to the process which leads to queen replacement in situ in dequeened colonies directly from brood present in the nest (Passera et al., 1988). This phenomenon constitutes additional evidence that the Argentine ant exhibits unusual possibilities of queen replacement contributing to its ecological success.

\section{SUMMARY}

Mated queens of the Argentine ant Linepithema humile inhibit dealation of winged virgin queens. Winged virgin queens never lay eggs. In the absence of mated queens, virgin queens shed their wings when they are 1 to 14 weeks old. Wing shedding triggers vitellogenesis, and egg laying occurs an average of 18 days later. Egg laying results in the rearing of males which are capable of mating with their dealated virgin mother. Overall, mated queens of the Argentine ant have similar effects as Solenopsis queens. They control dealation and the egg laying of the virgin winged queens.

\section{ACKNOWLEDGEMENTS}

This research was supported by a grant from the French Ministère de la Recherche et de 1'Espace to $S$. Aron and from the "European Network of Research Laboratories N 418210 57". We wish to thank E. Vargo for his helpful advice and suggestions and two anonymous referees for their comments and for improving the English text. 


\section{REFERENCES}

BRIAN, M. V.

1979. Caste differentiation and division of labor. In: Hermann, H. R. (ed) Social Insects, 1. Acad. Press, New York, 122-222.

Buschinger, A. And Petersen, M.

1971. Die Dauerzucht der Pharaoameise Monomorium pharaonis (L.) im labor. Anz. f. Schädlingsk. Pflanzensch. 44: 103-106.

DEJEAN, A.

1974. Etude du cycle biologique et de la reproduction de Temnothorax recedens (Nyl.) (Insecta Formicidae). Thèse, Université Paul-Sabatier, Toulouse, $155 \mathrm{pp}$.

Fletcher, D. J. C. AND Blum, M. S.

1981. Pheromonal control of dealation and oogenesis in virgin queen fire ants. Science. 212: 73-75.

1983. The inhibitory pheromone of queen fire ants: effects of disinhibition on dealation and oviposition by virgin queens. J. Comp. Physiol. A 153: 467-475.

Glancey, B. M., Glover, A. And Lofgren, C. S.

1981. Pheromone production by virgin queen of Solenopsis invicta Buren. Sociobiology 6: 119-127.

Goetsch, W. AND KaEthneR, B. R.

1937. Die Koloniegründung der Formiciden und ihre experimentelle Beeinflussung. Z. Morphol. u. Oekol. 33: 201-260.

Haskins, C. P. And Enzmann, E. V.

1945. On the occurrence of imparternate females in the Formicidae. J. N.Y. Ent. Soc. 53: 263-277.

Keller, L. AND PASSERA, L.

1992. Mating system, optimal number of matings, and sperm transfer in the Argentine ant Iridomyrmex humilis. Behav. Ecol. Sociol. 31: 359-366.

Keller, L., Passera, L. AND Suzzoni, J. P.

1989. Queen execution in the Argentine ant Iridomyrmex humilis (Mayr). Physiol. Entomol. 14: 157-163.

LOFGREN, C. S. AND Williams, D. F.

1984. Polygynous colonies of the red imported fire ant, Solenopsis invicta (Hymenoptera: Formicidae) in Florida. Fla. Ent. 67: 484-486.

Markin, G. P., Collins, H. L. And Dillier, J. H.

1972. Colony founding by queens of the red imported fire ant, Solenopsis invicta. Ann. Entomol. Soc. Am. 65: 1053-1058.

Newell, W. AND BARBER, T. C.

1913. The Argentine ant. USDA Bur. Entomol. Bull. 122: 98 pp.

PASSERA, L.

1978. Une nouvelle catégorie d'oeufs alimentaires: Les oeufs alimentaires émis par les reines vierges de Pheidole pallidula (Nyl.). Ins. Soc. 25: 117-126.

1992. Characteristics of tramp species. In: Williams D. F. (ed.) Exotic Ants: Biology, Impact and Control of Introduced Species. Westview Studies in Insect Biology. Westview Press, Boulder (in press). 
PAssera, L. AND Aron, S.

1993. Social control over the survival and selection of winged virgin queens in an ant without nuptial flight: Iridomyrmex humilis. Ethology 93: 225-235.

PASSERA, L. AND Keller, L.

1992. The period of sexual maturation and the age at mating in Iridomyrmex humilis, an ant with intranidal mating. J. Zool. Lond. 228: 141-153.

Passera, L., Keller, L. And Suzzoni, J. P.

1988a. Control of brood male production in the Argentine ant Iridomyrmex humilis (Mayr). Ins. Soc. 35: 19-33.

1988b. Queen replacement in dequeened colonies of the Argentine ant Iridomyrmex humilis (Mayr). Psyche 95: 59-66.

Petersen, M. And Buschinger, A.

1971. Das Begattungsverhalten der Pharaoameise Monomorium pharaonis (L.). Z. angew. Entomol. 68: 168-175.

Plateaux, L.

1970. Sur le polymorphisme social de la fourmi Leptothorax nylanderi (Förster). I. Morphologie et biologie comparées des castes. Ann. Sci. Nat. Zool., Paris 12: 373-478.

Sorensen, A. A., Fletcher, D. J. C. And Vinson, S. B.

1985. Distribution of inhibitory queen pheromone among virgin queens of an ant, Solenopsis invicta. Psyche 92: 57-69.

ToHmé, G.

1975. Ecologie, biologie de la reproduction et éthologie de Messor ebeninus Forel (Hymenoptera, Formicoidea, Myrmicidae). Bull. Biol. Fr. Belg. 59: 171-251.

TSCHINKEL, W. R. AND HowARD, D. F.

1978. Queen replacement in orphaned colonies of the fire ant, Solenopsis invicta. Behav. Ecol. Sociobiol. 3: 297-310.

VARGo, E. L. AND FletChER, D. J. C.

1987. Effect of queen number on the production of sexuals in natural populations of the fire ant, Solenopsis invicta. Physiol. Ent. 12: 109-116.

VArgo, E. L. AND PASSERa, L.

1991. Pheromonal and behavioral queen control over the production of gynes in the Argentine ant Iridomyrmex humilis (Mayr). Behav. Ecol. Sociobiol. 28: 161-169.

VARgo, E. L. AND Porter, S. D.

1993. Reproduction by virgin queen fire ants in queenless colonies: comparative study of three taxa (Solenopsis richteri, hybrid S. invicta/richteri, S. geminata) (Hymenoptera: Formicidae). Ins. Soc. (in press).

VArgo, E. L. AND Ross, K. G.

1989. Differential viability of eggs laid by queens in polygyne colonies of the fire ant, Solenopsis invicta. J. Insect Physiol. 35: 587-594.

Voss, S. H.

1981. Trophic egg production in virgin fire ant queens. J. Georgia Entomol. Soc. 16: $437-440$.

Willer, D. E., AND Fletcher, D. J. C.

1986. Differences in inhibitory capability among queens of the ant Solenopsis invicta. Physiol. Entomol. 11: 475-482. 

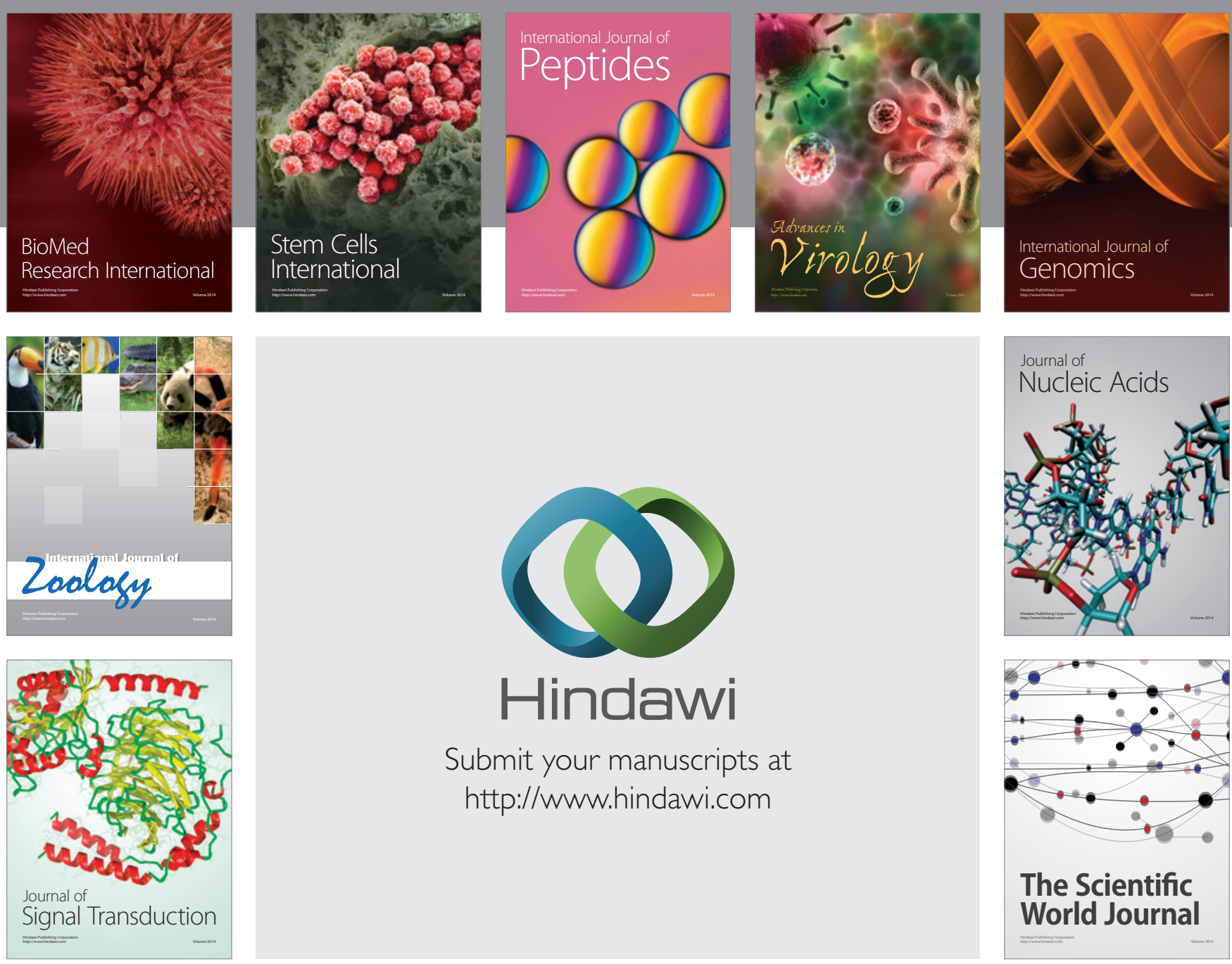

Submit your manuscripts at

http://www.hindawi.com
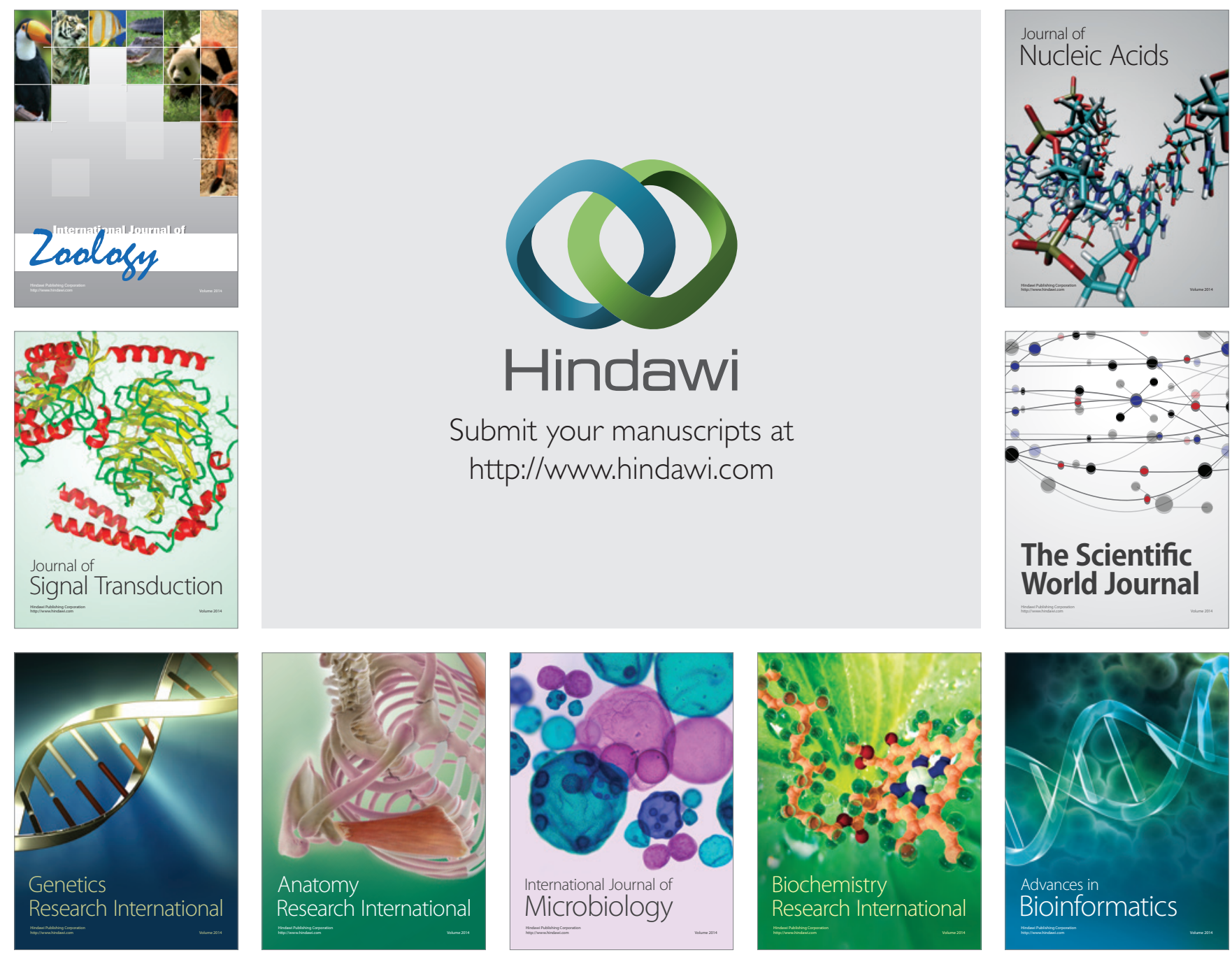

The Scientific World Journal
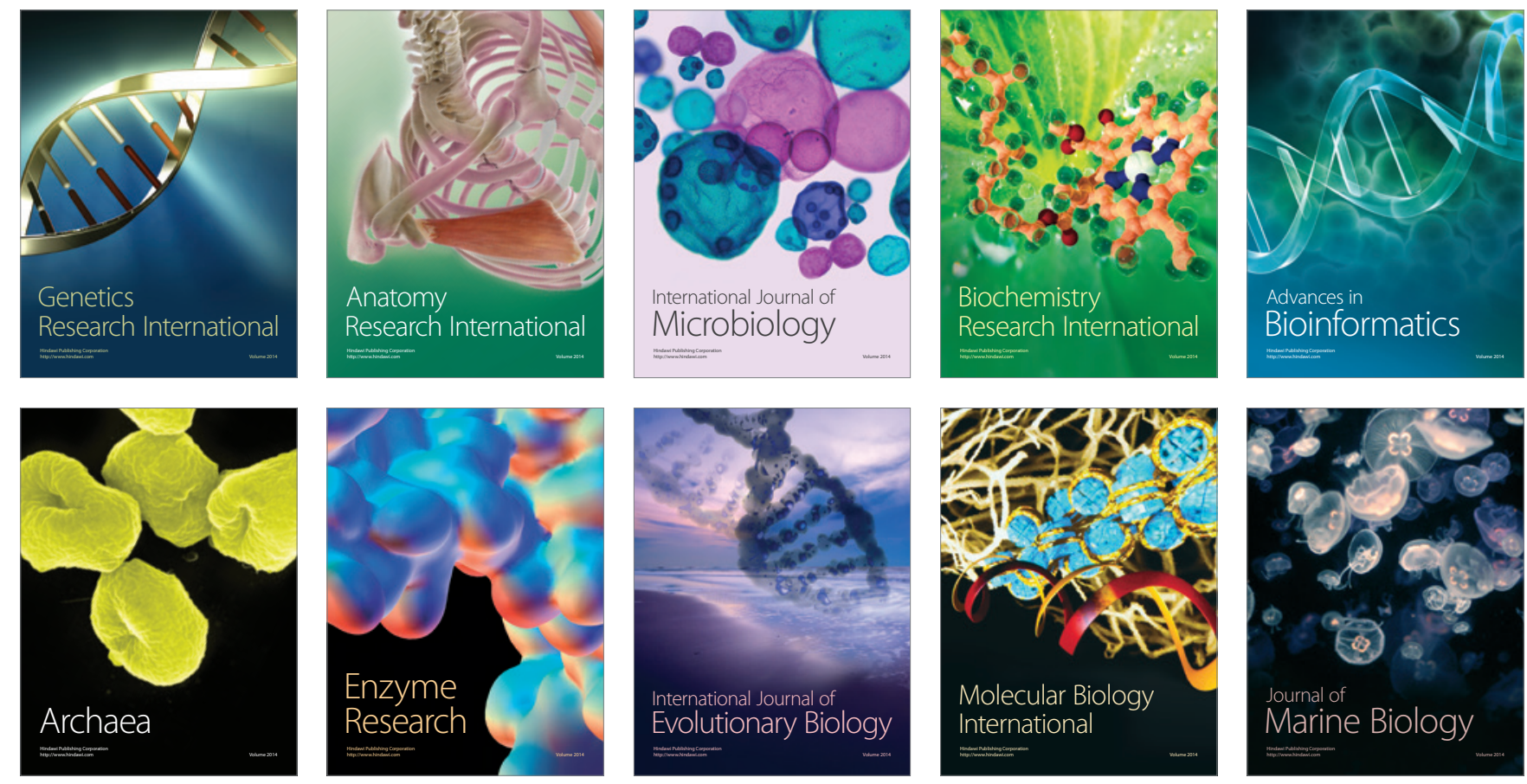